\title{
Law for Country: the Structure of Warlpiri Ecological Knowledge and Its Application to Natural Resource Management and Ecosystem Stewardship
}

\author{
Miles C. C. Holmes ${ }^{1,2}$ and Wanta (Stephen Patrick) Jampijinpa ${ }^{3}$
}

\begin{abstract}
Indigenous Ecological Knowledge (IEK) is deeply encoded in social processes. Our research shows that from an Indigenous perspective, IEK is a way of living whose core aim is to sustain the healthy functioning of people and country through relationships of reciprocity. However, IEK is often portrayed more prosaically as a body of knowledge about the environment. We introduce a framework, called ngurra-kurlu, that enables appreciation of indigenous perspectives on IEK. The framework was identified from the collaborative work of the authors with Warlpiri aboriginal elders in the Tanami Desert region of central Australia. Ngurra-kurlu facilitates cross-cultural understanding by distilling, from a complex cultural system, the five distinct conceptual categories that comprise IEK: law, skin, ceremony, language, and country. The framework enables engagement with nuanced environmental knowledge because it synthesizes, for cross-cultural audiences, all the key areas of knowledge and practice in which IEK is located. In particular, the framework highlights how social systems mediate the transmission, deployment, and regulation of environmental knowledge in on-ground situations, including collaborative natural resource management. Although the framework was generated in relation to one indigenous group, the epistemological structure of Warlpiri IEK is relevant throughout Australia, and the framework can be applied internationally to the emerging interest in fostering ecosystem stewardship in which the cultural connections between people and place are an integral part of ecosystems management.
\end{abstract}

Key Words: Aboriginal Australians; anthropology; central Australia; cultural natural resource management; ecosystem stewardship; indigenous ecological knowledge; indigenous knowledge; indigenous land management; Northern Territory, Australia; social-ecological systems; Warlpiri

\section{INTRODUCTION}

Indigenous ecological knowledge (IEK) can be an important part of collaborative natural resource management (NRM; Williams and Baines 1993, Johnson and Hunn 2010a, Ens and McDonald 2012). Here, we present a framework for IEK that can facilitate better integration between science and IEK. The framework was developed from original ethnographic research with Warlpiri aboriginal people of central Australia. The framework identifies all the key categories of knowledge and practice that constitute IEK. It is important to recognize that Warlpiri, as well as other indigenous peoples (see EvansPritchard and Gillies 1976), do not seek a consensus about the ontology of their knowledge systems. Beliefs, knowledge, and social rules are actualized rather than intellectualized; therefore, IEK for Warlpiri people is not just an idea but is experienced daily (see also Sathre 2003 in relation to the ontology of Warlpiri witchcraft). For this reason, a systematic description of what constitutes IEK is not readily identifiable from either emic or etic accounts. Although the cultural elements identified here as IEK have been considered separately in the Australian anthropological literature, this is the first attempt to synthesize them in a single framework. For indigenous Australian cultures more generally, it is one of only a few available holistic cultural frameworks (e.g., Hogan 2006, Dobson et al. 2008, Walsh et al. 2013).
The Warlpiri framework is called ngurra-kurlu, which is interpreted as "from country" or "country within [people]". As this translation suggests, ngurra-kurlu embodies the fundamental Warlpiri ethic of reciprocity between people and country; the meaning of country in aboriginal English usage is considered in detail below. Each entity is understood to support the healthy functioning of the other. This ethic of reciprocity is common across indigenous Australia in terms of the structure of environmental knowledge systems (e.g., Aboriginal Land Commissioner 1989). "Healthy country creates healthy people" is a common slogan from the Australian cultural resource management sector (Putnis et al. 2007) that is substantiated to some extent by available evidence (Burgess et al. 2005, 2009, Davies et al. 2011). However, our Warlpiri informants are consistent in also emphasizing the reciprocal relationship: healthy people, meaning functioning cultural systems that support peoples' physical and mental health, are a basic element of healthy country. Hence, while IEK research and practice has traditionally privileged engagement with factual knowledge about the "natural system" (Cunningham 2001), we pay particular attention here to demonstrating how IEK is practiced and transmitted through Warlpiri social institutions.

The ngurra-kurlu framework expresses how Warlpiri culture encodes IEK across the social-ecological system as well as in 
the particular cultural connections to land that facilitate a stewardship ethic. The ontological understanding that the land and people are one symbiotic unit, or one palka or body in Warlpiri metaphor, is compatible with linked socialecological theory (e.g., Berkes et al. 2003b, Halliday and Glaser 2011) in that both are characterized by an intent to consider socio-cultural, biological, and physical dimensions as one unit. This ontology also aligns with emerging interests in NRM toward fostering ecosystem stewardship (e.g., Folke et al. 2009). Ecosystem stewardship is an approach to management that is different from steady-state resource management, which manages for a single outcome. It is also different from ecosystem management that manages for multiple ecosystem services. Stewardship manages for fundamental social-ecological properties (Chapin et al. 2009a). Chapin et al. (2009a:16) state that ecosystem stewardship "recognizes managers as an integral component of the system that they manage" and, in support of a Leopoldian land ethic, ecosystem stewardship implies a "sense of responsibility for the state of the system of which we are part."

Contemporary definitions of IEK stretch to several paragraphs to capture the wide range of knowledge, practice, and beliefs that are understood to be part of IEK (e.g., Berkes 1999, Usher 2000, Berkes and Folke 2002, Houde 2007). Although these definitions encompass elements that constitute IEK and current typologies, they are meta-analyses that do not necessarily convey how IEK exists in situ. When indigenous people talk about their knowledge of country, it is frequently in the following style:

"Water from plants, fire, clouds, rain, sun, moon, stars, stories and sites, songs, paintings, dancing ... looking after country involved all these things together-you can't have one without the other. Maintaining language and culture is a tool for relating to country and looking after everything that is on it." Veronica Dobson, Arrernte Elder, quoted in North Australian Indigenous Land and Sea Management Alliance (2006:3).

Similarly, the Clayoquot Sound Scientific Panel (1995:15) summarizes a Canadian indigenous perspective in relation to IEK as: "The Creator made all things, all things are related and interconnected, all things are sacred and must be respected, balance and harmony are essential to all life forms."

Here, we call the domain that we are concerned with IEK. However, we recognize that no Warlpiri person would refer to their knowledge in a way that distinguishes ecology from other dimensions of their life. The strong emphasis on culturalist interpretations of nature in indigenous constructs of the meaning of IEK makes it difficult for indigenous people to communicate effectively with scientists and with most other people socialized in Western thinking, who are predisposed to see nature and culture as different ontological categories
(Ellen and Harris 2000). In the absence of adequate crosscultural understanding, engagement of IEK and science becomes fragmented in accordance with particular disciplinary approaches or policy frameworks. For example, ethnobotanists are concerned with the utility of plants (Cleland 1936, O'Connell et al. 1983, Barr et al. 1988), anthropologists with the cultural significance of nature (Myers 1986), policy analysts with the policy environment (Johnson and Hunn $2010 b$ ), and environmental scientists with ecological knowledge that may be applied to scientific land management practices (Cunningham 2001, Drew and Henne 2006).

Warlpiri studies are a case in point. The literature contains excellent research describing human relationships with the Warlpiri environment through the lenses of natural history (for example, Latz 1995), country (Faulstich 1990), language (Laughren et al. 2005), song (Glowczewski 2001), kinship (Meggitt 1962), ritual (Dussart 2004), and art and symbolism (Munn 1984). While these studies are important in their own right, increased understanding of complex adaptive systems (Walker and Salt 2006) has shown that the parts do not add up to the whole and that it is therefore also necessary to study the system in situ (Berkes et al. 2003a). Warlpiri people make a similar point by repeatedly demonstrating that it is the relationships between the parts that matter. However, the difficulty with this gestalt is that these interconnections are dynamic and are therefore also both complex and elusive (Strang 2005). Walker et al. (2006) state:

“...social ecological systems are neither humans
embedded in an ecological system nor ecosystems
embedded in human systems but rather a different
thing altogether. Although the social and ecological
components are identifiable, they cannot easily be
parsed for either analytic or practical purposes."

Our collaborative research has developed the ngurra-kurlu framework to show, for analytic and practical purposes, how knowledge and practice operate through relationships within the social-ecological system that is Warlpiri country and culture. Our aim is to present the framework and its interrelated elements. Before doing so, we introduce the Warlpiri people and their customary lands and describe our methods. We then describe each constituent element of the framework. Finally, we discuss how the framework is applicable to natural resource management at varying scales and, in particular, how ecosystem stewardship, as an environmental management approach, can be informed by the fundamental structures inherent in Warlpiri IEK.

\section{LOCATION AND ENVIRONMENTAL PROFILE}

This research was undertaken with Warlpiri aboriginal people from the community of Lajamanu in Australia's Northern Territory. Lajamanu is a community of approximately 800 Warlpiri language speakers located at the northern extent of the Tanami Desert, most of which is in Warlpiri country (Fig. 
1). The Lajamanu area is semi-arid with monsoonal influences. Seventy-five percent of rainfall occurs in the summer months, but rainfall patterns are extremely variable from year to year. Spinifex (hummock grass) covers most of the area, interspersed with salt pans, rocky rises, and intermittent watercourses. The vegetation overstory varies according to topography and includes species of Acacia, Corymbia, Eucalyptus, and Melaleuca (Northern Territory Government Department of Land Resource Management: http://lrm.nt.gov. au/herbarium/nature/bioregional/tanami). Termite mounds are abundant on the clayey soils of palaeodrainage channels. The fauna of the Tanami Desert is typical of the Australian arid zone except that some species usually associated more with the lower latitude wet-dry tropics occur around Lajamanu. Fire is an important feature of the landscape ecology. The country is burned regularly by Warlpiri people, who use fire as a key element of their interaction with the land. Warlpiri people's traditional knowledge is recognized and valued by government and nongovernment organizations operating in the region. Collaborations between scientists and Warlpiri knowledge holders are occurring in the management of fire, weeds, threatened species, water quality, biodiversity monitoring, and cultural maintenance. Two Indigenous Protected Areas (Davies et al. 2013) cover a large percentage of Warlpiri country.

Fig. 1. Map of Warlpiri country within Australia.

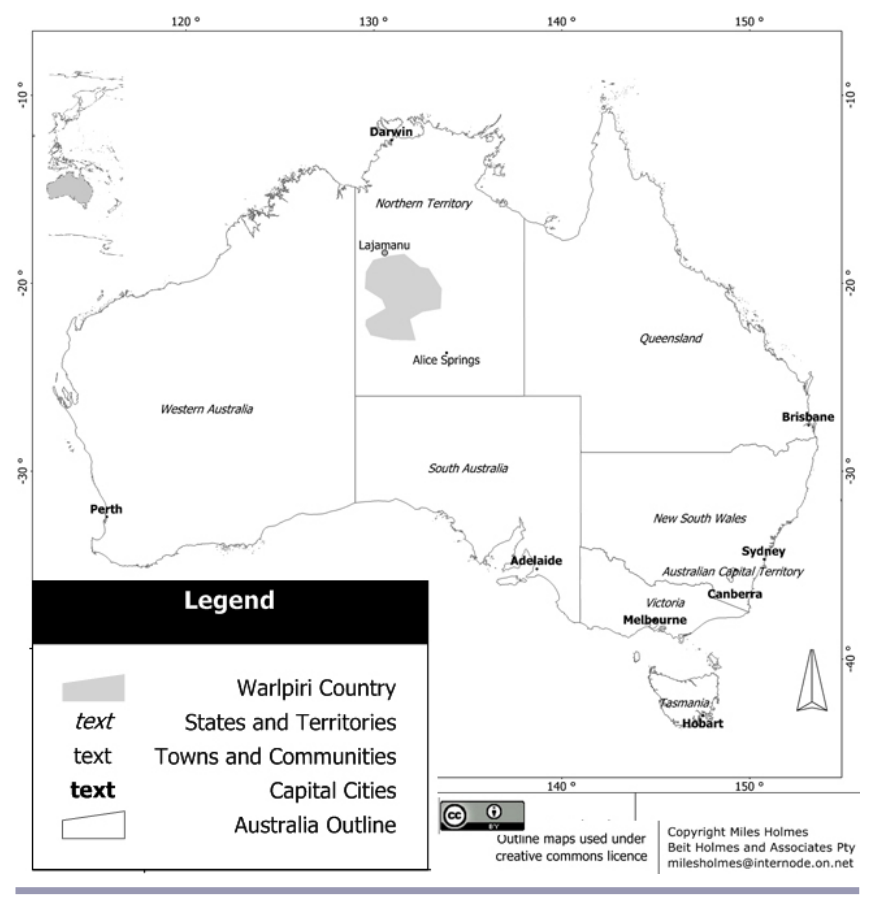

\section{METHODOLOGY}

This research and the framework presented here are the result of collaboration between people from different cultural backgrounds using different methodologies. Here, we explain each of our backgrounds and methodologies and then the methods we used to collaborate.

One of us (MH) is an anthropologist who has been working with Warlpiri in Lajamanu for 10 years as both a researcher and heritage consultant. This paper is partially informed by previous research (Holmes 2010) that used an ethnographic methodology with long-term field work. The methods were primarily participant observation and also included semistructured interviews. Other methods included community development projects such as commercial bushfood harvests and IEK revitalization country camps, which MH facilitated and subsequently evaluated. For this paper, $\mathrm{MH}$ has also drawn on a method of coproducing knowledge with indigenous people called narrative ethnography, which seeks to increase the voice of "the other" through active involvement of research participants in the coproduction of ethnographic accounts (Sluka and Robben 2007). An aspect of narrative ethnography is the inclusion of direct quotations from indigenous people.

One of us (WP) is a Warlpiri man whose cultural authority stems from his status as marliyarra, a Warlpiri term that indicates that WP has passed through the higher levels of Warlpiri ceremony and law. WP is bilingual in Warlpiri and English. He formerly worked as a cross-cultural liaison officer at the education center in his home community of Lajamanu and is currently employed on a three-year research grant with the Australian National University, College of Arts and Social Sciences. WP began to crystallize the ngurra-kurlu framework using a phenomenological approach that draws on customary knowledge that he had learned in a traditional manner, primarily through observation, ceremony, and mentoring, rather than lectures or discourse, which are less common Warlpiri teaching-learning styles. The framework was progressively elaborated through cross-cultural collaborations that involved WP and non-Warlpiri colleagues, in particular, $\mathrm{MH}$ and former Lajamanu educator Lance Box (see PawuKurlpurlurnu et al. 2008), and the Milpirri (Fig. 2) community development project (Tracks, Milpirri 05 [Jarda-Warnpa] 2005: http://tracksdance.com.au/milpirri-05-jarda-warnpa). His overall quest has been to find the relevance of Warlpiri cultural principles to contemporary living.

Our cross-cultural collaborative research to develop further the ngurra-kurlu framework uses open-ended discussion and semistructured interviews to elicit shared understandings. We recorded information in note books, artistic designs, and audio files. Our discussions often followed the Socratic Method in which ideas were evaluated against theoretical perspectives 
from epistemology, social anthropology, customary law, as well as peer review processes and perspectives from each coauthor's ongoing ethnographic research with Warlpiri elders. This methodology has generated a framework that represents the complexity of culture in terms of five key elements. The structure of the framework is unique. However, the data on which it is based are consistent with previous anthropological research findings and with customary Warlpiri knowledge. The ngurra-kurlu framework was originally published as a research monograph with a community development focus (Pawu-Kurlpurlurnu et al. 2008). Here, we introduce new material and narrow the context of ngurra-kurlu to relate specifically to IEK. A more in-depth explanation of ngurrakurlu and a case study of its meaning in relation to a single species, Acacia tenuissima, is provided by Holmes (2010).

Fig. 2. A graphical representation of the ngurra-kurlu framework for indigenous ecolocial knowledge.

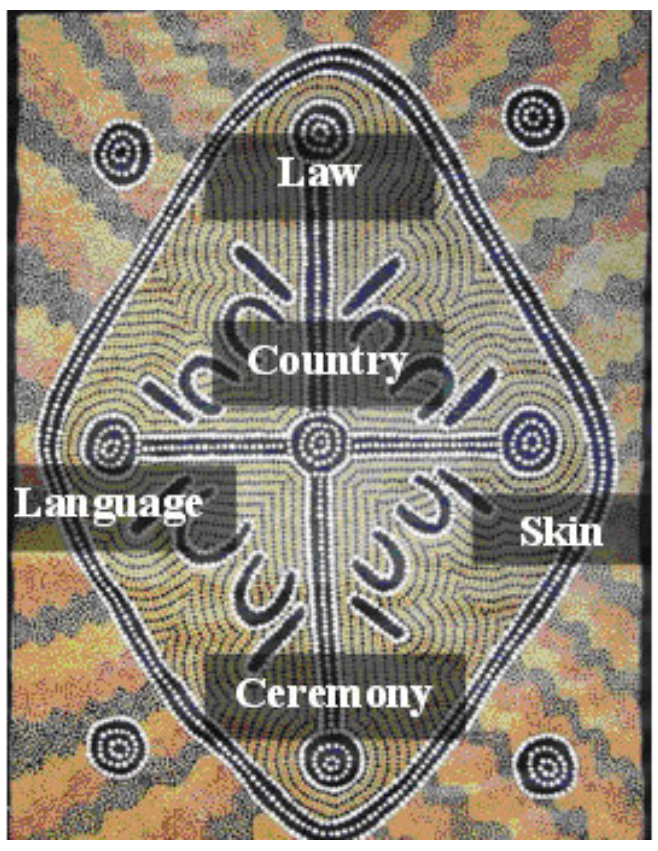

\section{RESULTS: NGURRA-KURLU FRAMEWORK FOR WARLPIRI INDIGENOUS ECOLOGICAL KNOWLEDGE}

Ngurra-kurlu is a representation of the five key elements of Warlpiri culture: law, skin, ceremony, language, and country (Fig. 3). These words have meanings that are different from the usual English language interpretations, encompassing different epistemic values. Like all anthropology, they are acts of translation.

To understand a plant or animal from a Warlpiri perspective, that is, to understand Warlpiri IEK, one conceptually places the organism in the center of the ngurra-kurlu framework and then explores each of the five cultural elements in relation to the organism. This exploration considers the law of the organism, its skin relationships, the ceremonies for the organism, Warlpiri language terms and also the way the organism communicates, and the country of the organism. Understanding of phenomena such as the wind and weather or elements of the physical landscape such as hills, rocks, and rivers can be developed in the same way. This process mirrors how Warlpiri people traditionally learn and teach about the environment, although in context, knowledge in relation to each element would be acquired at varying locations and over long periods of time.

Fig. 3. Dancers performing the ngapa-rain ceremony at the Milpirri cultural event at Lajamanu in 2012. The image illustrates ngurra-kurlu relationships to the ngapa (rain) narrative. The two men are the two hunters depicted in the story. Skin is represented through the color coding of performance clothes and banners, law through the banners in the background of the stage, and country through the ceremonial plant on the ground.

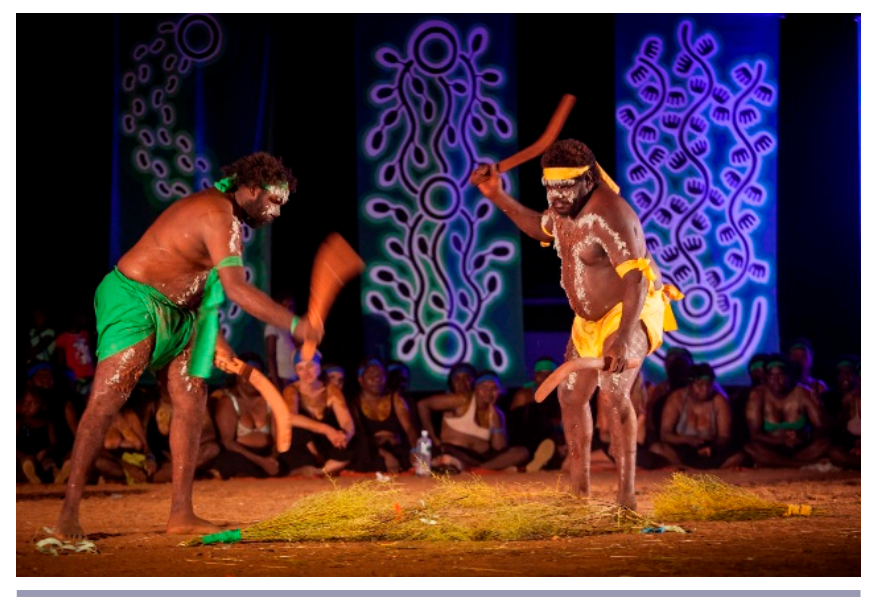

Each element of ngurra-kurlu is defined by its linkages with the other elements. Any one of the elements can be considered as a focus. However, the other elements will, by necessity, be included in the discussion. WP compares the codependency of elements to organs within palka, the body:

"Look at it this way. This ngurra-kurlu is palka: he's got his own heart, he's got his own kidneys, he's got his own liver. If you take one of them away, his whole body will drop - that way."

Skilled Warlpiri naturalists are marked by their ability to manipulate and combine information from the different elements of ngurra-kurlu to build understanding of a particular environmental observation or context. From a Warlpiri perspective, it is the connections rather than the individual elements that are of primary relevance. The meaning of each 
element and some of its inter-relationships with other elements are outlined below.

\section{Law: guiding principles}

If pressed to categorize knowledge in relation to a particular plant, animal, or ecosystem, most of our Warlpiri informants would call it kuruwarri, the law, or law for country. For Warlpiri, kuruwarri is the highest reference for direction about how to live in the world. It is a strict but adaptable code that can be conceived of at multiple levels of abstraction. In its most expansive sense, kuruwarri is the period widely known as "the dreaming" (Stanner 1969). During the dreaming, ancestral beings traveled over the landscape and, through actions such as singing, hunting, copulating, and performing ceremonies, created all the features of the physical and social world. The dreaming ancestors are simultaneously both human beings and either nonhuman species or phenomena such as weather events. The dreaming period continues in the present day in that ancestral beings are manifest throughout Warlpiri country as landforms, elements, and organisms and can interact with Warlpiri through their cultural practices.

The law is based in the narratives describing the dreaming ancestors' journeys. Narratives are in song format (Moyle 1997) and also include associated commentary, designs, body paintings, and sacred objects. The dreaming narratives follow a fixed path from place to place across the landscape and as such are also called songlines (Bradley 2010). Some songlines are localized, whereas others extend for hundreds or thousands of kilometers, crossing bioregions and language-group territories.

The law may be thought of as all the knowledge, beliefs, customs, practices, rules, and regulations of the Warlpiri way of life. It fulfills the same functions as mainstream culture's criminal and civil law as well as the ethics and codes of behavior established by secular and religious institutions. For example, the reasons why people should burn country, and the way that burning should be undertaken, are said to be the law for looking after country. The law is also akin to science in that it seeks to explain the functioning of the world. WP states:

\begin{abstract}
"See that tree. It is shedding its bark. No, we didn't tell it to do that. That is just its purpose, the kuruwarri [law] for that thing... If a plant is edible that is its kuruwarri. But it might also be there to teach yapa [aboriginal people] something. Like the seasons; they tell you what to do. Some things have purposes and limits - that's their law."
\end{abstract}

Dreaming narratives encode law for country, that is, the rules and knowledge needed to sustain country and also the rules and ethics of human behavior. They are also mnemonic maps of the land. Consider the extract from a traditional ngapa-rain narrative for which WP's family are trustees:

\begin{abstract}
"In a place near Kurlpurlurnu, two young warriors called warnmajarri-jarra were hunting for kanyarla [hill kangaroos, Macropus robustus]. The two young warriors lit a fire to flush the kangaroos out of the bush, but they realized that they had created a big bush fire that raged for days and was expanding. The bush fire created a big pillar of smoke that built up in the sky. The clouds were drawn into the pillar of smoke and created milpirri [cumulonimbus cloud], which then sent rain and drenched the land, putting out the fire." (Pawu-Kurlpurlurnu et al. 2008:25).
\end{abstract}

Information in this narrative that may be thought of as ecological knowledge concerns: the presence of hill kangaroos near the place called Kurlpurlurnu, a method to hunt hill kangaroos with fire, a warning about the dangers of creating a big bushfire, and the traditional understanding that the smoke particles from bushfires can seed clouds and cause rain.

At a higher level of abstraction, Warlpiri interpret this and other dreaming narratives as models or metaphors for how their social systems operate. In this example, the turbulent features of the milpirri cloud inform the philosophical underpinnings of the Jardiwarnpa ceremony, which is about reconciliation for wrongdoings. WP argues that the turbulent mix of hot and cold air in the cloud parallels the clash of emotions between arguing families. The rain that comes from the cloud puts out the fire and promotes new growth and is seen as complimentary to the reconciliation of wrongs and potential for positive family relationships that people feel after the Jardiwarnpa ceremony.

This dreaming narrative demonstrates the reciprocal relationship that exists between people and country. In this case, the law encodes information about the natural environment, which conversely informs Warlpiri understanding of how and why their social systems function. WP also noted a more pragmatic link that can influence land management: "Jardiwarnpa [reconciliation ceremony] is looking after country because if everyone is fighting, who's got time to look after country?" (Pawu-Kurlpurlurnu et al. 2008:26).

\section{Skin: responsibilities to people and country}

Warlpiri culture classifies people and also features of the environment into eight different social groups known as skin groups. These groups are called subsections in the anthropological literature and are a short-hand reference to the broader kinship system, a discussion of which is beyond the scope of this paper (see Meggitt 1972).

The names of skin groups are derived from the actions of ancestors in the dreaming period. A Warlpiri person's skin name is akin to a communal essence because it is shared by all members of the patriline (Munn 1996). Skin names also extend to aspects of the natural environment with which dreaming ancestors are associated: All people, plants, animals, 
areas of country, as well as phenomena such as the stars and rain have skin names and are implicated in the same kinship system. For example, the emu (Dromaius novaehollandiae) dreaming ancestor is of the N/Jampijinpa and N/Jangala skin group, where the $\mathrm{N}$ indicates the initial sound in the female skin name and $\mathrm{J}$ in the male skin name. People who are members of these two skin groups through patrilineal descent are called kirda in relation to emu, which means that they are trustees (called owners or bosses in aboriginal English) for the emu traditional knowledge. This means that they have responsibilities for the dreaming song, story, ceremony, the country through which the ancestor traveled, and, to a certain extent, the ongoing health of the biophysical species. Through matrilineal descent, other groups are kurdungurlu (called managers or policemen in aboriginal English) in relation to emu and have a different set of responsibilities toward emu traditional knowledge that include making sure that the kirda undertake their responsibilities properly. All the physical and social manifestations of the emu dreaming ancestor are implicated in the skin system. In this way, skin brings people and nature into the same realm and, through connections with kuruwarri-law, prescribes certain rights, obligations, and relationships. WP surmises:

"Skin starts with yourself. It is about relationships to people, place, and country. Skin is a system of relatedness, connectedness, how things integrate, roles, functions, boundaries, limits."

In relation to IEK, skin functions as a governance structure that controls access rights and land tenure, individual and group rights to benefit from the land, rights to burn, obligations to care for country in both contemporary and traditional frameworks, and obligations to hold and transmit knowledge. Rights and obligations for Warlpiri law and country are not held communally by all Warlpiri people. Rather they are apportioned across the various skin groups. WP states, "Skin is like a copyright over knowledge; one group cannot invade another" (Pawu-Kurlpurlurnu et al. 2008:13). However, rights and obligations are also not exclusive, as each family group is expected to act as a trustee for their particular knowledge and country on behalf of the whole.

\section{Language: communication between the elements}

Although no ethno-classificatory studies exist for Warlpiri, the Warlpiri dictionary (Laughren et al. 2005) makes it clear that Warlpiri have an extensive vocabulary for the natural world. Warlpiri language has co-evolved with Warlpiri epistemic and ontological values and is therefore essential to expressing the nuances of IEK.

Each element of ngurra-kurlu has its own language. Together, these languages facilitate the smooth functioning of the socialecological system that encompasses Warlpiri people. Skin language is the way in which people change speech depending on their audience. Ceremony language is the metaphorical language of songs, the meanings coded onto sacred objects, and the ceremonial body movements that imitate plants and animals. Law language is the ability of a person to use all the other languages to their full effect, including the different registers of spoken Warlpiri such as formal or high Warlpiri. Country language is all the Warlpiri names for the land and things in it. Country language can be onomatopoeic such as for bird names formed in imitation of the bird's voice. The diamond dove (Geopelia cuneata) is called kurlukuku, the crow (Corvus sp.) is kaarnka, and the zebra finch (Poephila guttata) is called jiyiki.

Warlpiri also recognize that the land can talk to Warlpiri people. This language includes the nonverbal body language of country. Seasonal indicators are one example: Warlpiri understand that when acacia flowers fall to the ground, snakes are mating and are therefore aggressive, and people should be careful when they are out hunting (see Hoogenraad and Robertson 1997, Prober et al. 2011). This indicates how Warlpiri IEK links botany, biology, and human ecology in a single understanding.

\section{Ceremony: education and unity}

Ceremony consists of the rituals in which the actions of the dreaming ancestors are recreated. There are many different kinds of Warlpiri ceremony, and most Warlpiri ethnographers have considered the nature and function of ceremony (Meggitt 1962, Dussart 2000). In our experience, nonindigenous people rarely see past the entertainment, religious, and/or supernatural associations that they ascribe to the ceremonies of Warlpiri and other indigenous peoples. They tend to see ceremony as unrelated to either natural resource management or science. However, ceremony is a critical aspect of Warlpiri environmental knowledge and stewardship of the land. Warlpiri people describe ceremony as education. Elders state that their people must go through different levels of ceremonies, which are akin to primary school, high school, and then university. WP compares ceremony to a text book in that engaging in ceremony is a process that imparts knowledge. Although a person will learn important information about any species through traveling over the land with their peers and elders, the deeper significance of how a plant or animal relates to the wider environment and to Warlpiri culture, that is, the complexity of IEK, is learned through ceremony. WP states:

\section{"Ceremony tells you when the seasons come [the language of country], it tells you why that berry tastes bitter or why it tastes sweet [the law]. Ceremony tells you who it belongs to and who has to look after it [kinship]."}

Warlpiri ceremonial songs can contain considerable specific IEK pertinent to species of plants and animals (for examples, see Holmes 2010). Elders state that for those who have 
graduated through the different levels of knowledge acquisition, ceremony is a celebration and a refreshment of knowledge.

\section{Country: home and identity}

The term country, which is common in aboriginal English in remote regions of Australia, is often assumed by mainstream NRM practitioners and scientists to mean the material landscape, the flora and fauna, and landforms. However, for Warlpiri, country is defined by its linkages with the other elements in the ngurra-kurlu framework (Fig. 3). Country is the biophysical world as understood through its associated law, skin, ceremony, and language. The phrase "a common sense of belonging" emerged from our research as an acceptable translation of the Warlpiri concept of country, encompassing the physical environment but also the various social, spiritual, and cultural relationships that transform an ecological landscape into a socio-cultural one. Anthropologists such as Faulstich (1994) and Myers (1986) have proposed that country is so deeply ingrained in the fabric of Aboriginal culture that it becomes akin to identity, and all activities are underpinned by a broad concept of spiritual and physical unity with the land. Maddock (1972) notes that the result is more akin to the land possessing people than people possessing the land. In Warlpiri, it is not uncommon for people to say that they hold the land, using the Warlpiri term mardarni, which means to have or to hold. This describes a different, more intimate relationship than owning or caring for the land. The term home is also useful in framing the role of country in Warlpiri IEK, as this term is understood cross-culturally to include more than the material house, camp, or country (see also Jackson 1995).

In Warlpiri usage, country includes: particular names for species or landforms that are either general or specific, sacred or profane; landforms created and maintained by the power of dreaming ancestors (e.g., the path of the emu ancestor is known as emu country); the songlines and law linked with particular places; the people of the right skin group who share a communal essence with the land; ceremonial designs, which stem from the land; and recognition that learning about country must include direct experience of the land.

WP presents country as fundamental to Warlpiri being and identity, saying "If we live in the community [of Lajamanu], we will be yapa [aboriginal people], but if we go on country, then we will be Warlpiri." Country as home is also fundamental to the coherence of all the other elements of ngurra-kurlu. WP uses a metaphor to describe this: "Consider a music player: ipod or walkman. The
battery is people, and the battery charger is
ceremony. Sometimes batteries goflat and die if they
are not recharged. So too if people are not going to
ceremony. They will not be refreshing or learning
their knowledge about country. The knowledge for people is like the electricity for the battery. Now, the place where you put that battery is its little homeit slots in there. Similarly, Warlpiri peoples' home should be on their country: they belong there; it's the right place for them. When the electricity, the battery, and the slot all come together, then you can turn on the music player and listen to it: the whole system is functioning. You can learn from it now: learn to sing that song, to talk that language, that language of country."

\section{DISCUSSION: STRUCTURE AND APPLICATION OF WARLPIRI INDIGENOUS ECOLOGICAL KNOWLEDGE}

The ngurra-kurlu framework can assist the integration of IEK with science by highlighting all the elements in Warlpiri culture that encode ecological knowledge and practices. Warlpiri IEK in relation to any organism or phenomenon may be considered as the relationships between different knowledge types as represented by the five elements of the framework. These knowledge types are often separated in mainstream critical enquiry, and the relationships between them are obscured. Therefore, Warlpiri IEK does not map easily onto Western understandings of ecological knowledge or disciplines such as botany or biology. No body of Warlpiri ecological knowledge emerged from our research that could be separated from a broader body of Warlpiri knowledge. Rather Warlpiri IEK is fully embedded within its cultural context.

The integration of IEK with science has often been characterized by a pervasive Eurocentrism that has reduced IEK to those aspects that are consistent with mainstream methods and epistemologies (Usher 2000, Baker et al. 2001, Bicker et al. 2004, Johnson and Hunn 2010b, Prober et al. 2011, Houde 2007). This flawed practice is also linked with a continuing disciplinary divide between the natural and social sciences so that despite increasing awareness of the reality of linked social-ecological systems, cross-fertilization of ideas remains poor (Head et al. 2004). The key to IEK-science integration is to recognize all categories of knowledge as valuable in context (Fortmann 2008, Murphee 2008). Although many differences exist, there are also similarities and opportunities for collaboration (Agrawal 1995). However, these are difficult to appreciate when the authority of one system of knowledge is subjugated to the other (Chapin 2009). Here, we discuss the potential application of the ngurra-kurlu framework to develop better practice for IEK-science integration, overcoming disciplinary and epistemological divides. We first discuss this potential in the Warlpiri context. We then consider the relationship between the framework and Australian and global understandings of indigenous knowledge. Finally, we discuss the contributions that the ngurra-kurlu framework makes to the concept of ecosystem stewardship. 


\section{Application within Warlpiri natural resource management projects}

The ngurra-kurlu framework is a tool that highlights those elements that must be considered if Warlpiri communitybased land management projects are to be culturally relevant. Most such projects are coordinated by non-Warlpiri NRM practitioners, who have been socialized to see nature and culture as separate and have been trained within a Western disciplinary framework (Woodward 2008, Davies et al. 2011, 2013). Use of the ngurra-kurlu framework can help such practitioners to ensure that all aspects of Warlpiri IEK are fully engaged and that local institutions are strengthened, thus empowering Warlpiri communities. Such outcomes are important preconditions for advancing long-term conservation goals (Berkes et al. 2009).

As an example of using the framework for this purpose, we consider the situation of a non-Warlpiri practitioner who coordinates a threatened species program, for example, and may seek to record and revitalize Warlpiri knowledge about a particular species. The ngurra-kurlu framework indicates that information about the species is held and transmitted by Warlpiri people in a variety of cultural contexts: law, skin, ceremony, language, and country. With careful research, it would be possible for the coordinator to assemble a montage of facts, stories, songs, and pieces of ceremony that could represent Warlpiri IEK for the species. Such a process would help to counter a common criticism that science codifies IEK by only considering those aspects of knowledge that are compatible with the underlying tenants of scientific method such as objectivity and materialism (Ellen and Harris 2000, Bicker et al. 2004). However, even though compiling knowledge about a species might be desirable for a specific purpose, the process is unlikely to foster revitalization of that knowledge because it does not engage with how the knowledge exists in situ. Warlpiri people would find an accumulation of information in relation to each ngurra-kurlu element only partially relevant because it would not practically engage with the social institutions or the political contexts through which they negotiate, teach, learn, modify, and practice their environmental knowledge. Hence, following authors such as Bradley et al. (2006) and Huntington et al. (2006), we consider that it is important to resist the common tendency to transform ecological knowledge into something abstract and objective rather than something that is lived day to day.

The ngurra-kurlu framework reveals the potential for an alternative approach. One option would begin the threatened species program with a parnpa, or public ceremony, for the species of interest. The ngurra-kurlu framework indicates that starting with ceremony will immediately activate the linkages between a species and all the other elements of ngurra-kurlu. Ceremony would refresh knowledge about the species (law); engage the appropriate elders and senior knowledge holders (skin); draw out knowledge such as language, songs, dances, and designs (language and law); catalyze negotiation about the ownership and sharing of knowledge (skin); renew relationships between the relevant families who might work on the project (skin); create discussion of the country and habits of the species (country); and raise awareness of the species in a respectful fashion (law). As well as activating information in relation to each element of ngurra-kurlu, ceremony also catalyzes the social and political processes that are necessary for knowledge to be transformed into practice.

Another potential starting point for modes of NRM engagement and IEK-science integration that are appropriate to Warlpiri ontologies and epistemologies would be to start with the country element of the ngurra-kurlu framework through a field trip onto country. Warlpiri people regularly propose this starting point in cross-cultural planning for all types of community projects in areas such as education, health, law and order, and especially in relation to land management works. However, because Warlpiri field trips focus around hunting or gathering, external observers commonly see them as "a somewhat quirky, picnic-type activity" (Walsh 2000:16) and fail to take them seriously. In contrast to this portrayal, a Warlpiri field trip actually uses all the elements of ngurrakurlu to transmit knowledge and to create strong connections between people and place. For example, an observer might notice Warlpiri field trip participants tracking threatened species of interest, animal tracks being a commonly recorded aspect of IEK. A more astute observer might also witness Warlpiri elders teaching young people the skin name for the species, ahead of teaching the actual species name (see also Bradley et al. 2006). Knowing the skin name informs the learner of their own social obligation to the species and identifies which other families share the responsibility. Young people are then led to understandings about the dreaming story and song. This may occur during evening ceremony because, as previously discussed, ceremony contains ecological facts about the species and broad-scale instruction about the correct way to observe country. If the country visit also occurs in the ancestral dreaming country of the species of interest, learners gain perspectives that enable them to extend their own mental map of that species' traditional area.

The salient outcome of a ngurra-kurlu-based Warlpiri country visit is that the ecological landscape is transformed into a social one. In this example, kinship is an important part of IEK, not simply because of the fact that a species of interest has a particular skin name, but because of what knowledge of that skin name means for Warlpiri people. Knowledge of the skin name activates the cultural responsibilities of particular groups of Warlpiri, conveys to Warlpiri their entitlements to access land and knowledge related to the species, and shows what and how they are required to teach their children about the species. Although simple information such as track identification is very useful for biological surveys or field guides, the ngurra-kurlu framework highlights that this is only 
one aspect of environmental knowledge. Such factual information must be linked with the social systems to activate appropriate mechanisms for knowledge to be transformed into practice.

At this scale, the distinction between IEK as a system of knowledge and other aspects of Warlpiri knowledge disappears. IEK is not a commodity in which facts are learned by rote and added to the toolbox of management techniques. Rather, IEK is a process that Warlpiri engage with throughout their lives. In this process, the systems of knowledge and behavior that sustain country also sustain people's lives. Faulstich (1990) introduces the term "mutual tenureship" to describe this reciprocal arrangement, and Rose (1995) identifies that sustaining the healthy functioning of people and of country are not seen as separate pursuits but as a natural part of living.

\section{Application to understanding indigenous ecological knowledge beyond Warlpiri country}

The ngurra-kurlu framework distills, from the complexity of Warlpiri culture, the key elements of a particular socialecological system. The framework is at a level of analysis that Walsh et al. (2013) refer to as meso-level, meaning that it is located above the micro-level detail of species information but below the macro-level of IEK definitions. Ngurra-kurlu has relevance as a heuristic tool beyond the local context because it represents fundamental elements of human-environment relations, which are, to a large degree, common to all Australian indigenous groups (see Radcliffe-Brown 1926, Horton 1994). Indeed, the ngurra-kurlu framework has been used in applications and geographical regions that are different from its genesis. For example, it has been used as a case study in national Indigenous Protected Area planning guidelines (Hill et al. 2011) and as an example of how indigenous frameworks can inform underlying methodologies (O'Neill et al. 2012). Low Choy et al. (2010) state that ngurra-kurlu is a case study that strongly correlates with the indigenous landscape values identified in regional planning workshops held in urban, semi-urban, and regional areas of southeast Queensland. This is significant because it indicates that the ngurra-kurlu framework can be applicable to collaboration with indigenous groups at different levels of engagement, in different landforms to Warlpiri country, and with groups that have different cultural histories than the Warlpiri.

The framework is also compatible with global discourses from environmental anthropology, which alert us to the general structure of indigenous knowledge (IK), namely that, IK is shaped by associations with the natural environment, human beings are considered an inherent part of a complex set of interactions between people and place, and IK is not static or hermetically sealed from the wider world and its environmental or social influences (Rappaport 1968, Stewart 1995, Descola and Pálsson 1996, Ellen and Fukui 1996, Ingold
2000, Geertz 2008 [1972]). This compatibility indicates that the ngurra-kurlu framework is valuable for informing general principles of IEK-science integration. Following eminent anthropologist W. E. H. Stanner (1969), who wrote of patterns of experience and thought apparent within Aboriginal symbolic systems that are vital to social life across the borders of language and culture, we further suggest that the elements and inter-relationships that constitute the ngurra-kurlu framework also hold relevance for all human-nature interactions and for ecosystem stewardship.

\section{Ecosystem stewardship and the structure of Warlpiri indigenous ecological knowledge}

Chapin et al. (2010) describe the trend in ecosystem management in moving away from steady-state resource management and a science-of-the-parts approach toward managing well-being across the natural and social systems. This new approach is termed ecosystem stewardship (Chapin et al. 2009b). Its central goal is in sustaining the capacity of ecosystems to provide services that benefit society by focusing management on the integrity of ecosystems as well as on the adaptive capacity and well-being of society. This inherent reciprocity, which integrates human and ecosystem wellbeing, underlies Warlpiri IEK and indigenous world views more generally.

In efforts to develop an ethic of ecosystem stewardship, pathways that build or maintain cultural connections between people and place are especially important but are also difficult to identify and facilitate (Balmford and Cowling 2006, Berkes et al. 2009, Chapin 2009, Swanson and Chapin 2009). We postulate that the cultural connections between people and place that are required to develop an ethic of stewardship will include the patterns evident in the ngurra-kurlu framework. Although the specifics will necessarily be different among different peoples and localities, structural elements and relationships of cultural connection that we postulate as universal are healthy country, that is, land, water, and other natural resources that humans relate to like a home; binding and respected laws; ceremony, or education, that connects people to, celebrates, and teaches about country; language to perceive the country and to communicate with and about country; and a degree of kinship between humans and the natural world that encodes rights and obligations for engagement with country.

Cultural connections to land, particularly those that inform group identity, "strongly influence peoples' sense of stewardship" and offer "excellent opportunity for natural resource managers to both learn from and contribute to stakeholder efforts to sustain livelihoods and environments" (Chapin 2009:56). Similarly, in the marketing of biodiversity "more love, less loss" is a slogan created by the Futerra Agency (Futerra Sustainability Communications 2010). It is based on the understanding that building positive and empathic 
connections with nature are more likely to stimulate biodiversity conservation action than connecting people with messages about environmental degradation (see also Chapin 2009). Futerra Sustainability Communications (2010) argues that "people will protect nature because they want to, not because they have to." We expect that efforts to replicate the structure of Warlpiri IEK in mainstream NRM will foster cultural connections between people and place that will help to generate a more general sense of stewardship for socialecological systems.

\section{CONCLUSION}

The holistic nature of IEK challenges the assumptions and methodologies of most science disciplines. Hence, integrating IEK and science remains one of the most difficult epistemological challenges for practitioners working crossculturally in NRM. Successful integration may require, as Murphee (2008:xix-xx) notes, "a degree of epistemological ecumenicism" that could ultimately be good for scholarship and practice. We identified that the integration of IEK and science would benefit from a greater appreciation of how IEK exists within the social-ecological system that is Warlpiri country and culture. Our structural analysis of the different categories of knowledge and practice in which Warlpiri IEK is embedded indicates that Warlpiri IEK is underpinned by a consistently applied cultural logic. This is reflected in the ngurra-kurlu framework in terms of inter-relationships between five elements: law, skin, ceremony, language, and country. Although developed specifically in relation to one indigenous group, the ngurra-kurlu framework is a meso-level analysis whose structure and core elements are expected to be more broadly applicable among Australian indigenous groups and are consistent with international understandings of the structure of indigenous knowledge. On this basis, we consider that engaging with the ngurra-kurlu framework will allow scientists and NRM practitioners to better understand IEK.

The Warlpiri perspective that underpins our research reveals that, when learned and practiced in a cultural context, IEK is a system that produces good naturalists and also immerses people in the social institutions through which knowledge is encoded, transmitted, and deployed on the landscape. Engagements between scientists and indigenous people that work with and through these social institutions are likely to promote effective collaborations in NRM. Our research reveals that the emergent purpose of Warlpiri IEK is to support the healthy functioning of people and environment in reciprocal relationships. It further suggests that elements and relationships underpinning the structure of Warlpiri IEK inform broader understandings of the cultural connections between people and place that are critical to the emergence of ethics of ecosystem stewardship.
Responses to this article can be read online at: http://www.ecologyandsociety.org/issues/responses. php/5537

\section{LITERATURE CITED}

Aboriginal Land Commissioner. 1989. Aboriginal Land Rights (Northern Territory) Act 1976: Kidman Springs/Jasper Gorge land claim. Report no. 30. Findings, recommendation and report of the Hon. Mr. Justice Olney, Aboriginal Land Commissioner, to the Minister for Aboriginal Affairs and to the Administrator of the Northern Territory. Australian Government Publishing Service, Canberra, Australia. [online] URL: http://www.fahcsia.gov.au/sites/default/files/ documents/05_2012/30_1.pdf.

Agrawal, A. 1995. Dismantling the divide between indigenous and scientific knowledge. Development and Change 26 (3):413-439. http://dx.doi.org/10.1111/j.1467-7660.1995.tb00560. $\underline{\mathrm{X}}$

Baker, R., J. Davies, and E. Young. 2001. Working on country: listening, sharing, and providing practical support. Pages 337-343 in R. Baker, J. Davies, and E. Young, editors. Working on country: contemporary indigenous management of Australia's lands and coastal regions. Oxford University Press, Melbourne, Australia.

Balmford, A., and R. M. Cowling. 2006. Fusion or failure? The future of conservation biology. Conservation Biology 20 (3):692-695. http://dx.doi.org/10.1111/j.1523-1739.2006.00434. $\underline{\mathrm{x}}$

Barr, A., J. Chapman, N. Smith, and M. Beveridge. 1988. Traditional bush medicines: an Aboriginal pharmacopoeia. Greenhouse Publications, Richmond, Australia.

Berkes, F. 1999. Sacred ecology: traditional ecological knowledge and resource management. Taylor \& Francis, Philadelphia, Pennsylvania, USA.

Berkes, F., and C. Folke. 2002. Back to the future: ecosystem dynamics and local knowledge. Pages 121-146 in L. H. Gunderson and C. S. Holling, editors. Panarchy: understanding transformations in human and natural systems. Island Press, Washington, D.C., USA.

Berkes, F., J. Colding, and C. Folke. 2003a. Introduction. Pages 1-29 in F. Berkes, J. Colding, and C. Folke, editors. Navigating social-ecological systems: building resilience for complexity and change. Cambridge University Press, Cambridge, UK.

Berkes, F., J. Colding, and C. Folke. 2003b. Navigating socialecological systems: building resilience for complexity and change. Cambridge University Press, Cambridge, UK. 
Berkes, F., G. P. Kofinas, and F. S. Chapin, III. 2009. Conservation, community, and livelihoods: sustaining, renewing, and adapting cultural connections to the land. Pages 129-148 in F. S. Chapin, III, G. P. Kofinas, and C. Folke, editors. Principles of ecosystem stewardship: resilience-based natural resource management in a changing world. Springer, New York, New York, USA. http://dx.doi.org/10.1007/978-$\underline{0-387-73033-2 \quad 6}$

Bicker, A., P. Sillitoe, and J. Pottier. 2004. Preface. Pages xixiv in A. Bicker, P. Sillitoe, and J. Pottier, editors. Investigating local knowledge: new directions, new approaches. Ashgate, Aldershot, UK.

Bradley, J. 2010. Singing saltwater country: journey to the songlines of Carpentaria. Allen \& Unwin, Sydney, Australia.

Bradley, J., M. Holmes, D. N. Marrngawi, A. I. Karrakayn, J. Miller, W. Ninganga, and I. Ninganga. 2006. Yumbulyumbulmantha ki-Awarawu $=$ all kinds of things from country: Yanyuwa ethnobiological classification. Aboriginal and Torres Strait Islander Studies Unit, University of Queensland, Brisbane, Australia.

Burgess, C. P., F. H. Johnston, H. L. Berry, J. McDonnell, D. Yibarbuk, C. Gunabarra, A. Mileran, and R. S. Bailie. 2009. Healthy country, healthy people: the relationship between Indigenous health status and "caring for country". Medical Journal of Australia 190(10):567-572.

Burgess, C. P., F. H. Johnston, D. M. J. S. Bowman, and P. J. Whitehead. 2005. Healthy country: healthy people? Exploring the health benefits of Indigenous natural resource management. Australian and New Zealand Journal of Public Health 29(2):117-122. http://dx.doi.org/10.1111/j.1467-842X.2005. tb00060.x

Chapin, F. S., III. 2009. Managing ecosystems sustainably: the key role of resilience. Pages 29-54 in F. S. Chapin III, G. P. Kofinas, and C. Folke, editors. Principles of ecosystem stewardship: resilience-based natural resource management in a changing world. Springer, New York, New York, USA.

Chapin, F. S., III, S. R. Carpenter, G. P. Kofinas, C. Folke, N. Abel, W. C. Clark, P. Olsson, D. M. Stafford Smith, B. Walker, O. R. Young, F. Berkes, R. Biggs, J. M. Grove, R. L. Naylor, E. Pinkerton, W. Steffen, and F. J. Swanson. 2010. Ecosystem stewardship: sustainability strategies for a rapidly changing planet. Trends in Ecology and Evolution 25(4):241-249. http:// dx.doi.org/10.1016/j.tree.2009.10.008

Chapin, F. S., III, G. P. Kofinas, and C. Folke. 2009a. A framework for understanding change. Pages 3-28 in F. S. Chapin III, G. P. Kofinas, and C. Folke, editors. Principles of ecosystem stewardship: resilience-based natural resource management in a changing world. Springer, New York, New York, USA.
Chapin, F. S., III, G. P. Kofinas, C. Folke, S. R. Carpenter, P. Olsson, N. Abel, R. Biggs, R. L. Naylor, E. Pinkerton, D. M. Stafford Smith, W. Steffen, B. Walker, and O. R. Young. 2009b. Resilience-based stewardship: strategies for navigating sustainable pathways in a changing world. Pages 319-337 in F. S. Chapin III, G. P. Kofinas, and C. Folke, editors. Principles of ecosystem stewardship: resilience-based natural resource management in a changing world. Springer, New York, New York, USA.

Clayoquot Sound Scientific Panel. 1995. First Nations' perspectives relating to forest practices standards in Clayoquot Sound. Report 3. Scientific Panel for Sustainable Forest Practices in Clayoquot Sound, Tofino, Canada. [online] URL: http://www.cortex.ca/dow-cla.html.

Cleland, J. B. 1936. Ethnobotany in relation to the central Australian Aboriginal. Mankind Quarterly 2(1):6-9.

Cunningham, A. B. 2001. Applied ethnobotany: people, wild plant use and conservation. Earthscan, London, UK.

Davies, J., D. Campbell, M. Campbell, J. Douglas, H. Hueneke, M. LaFlamme, D. Pearson, K. Preuss, J. Walker, and F. Walsh. 2011. Attention to four key principles can promote health outcomes from desert Aboriginal land management. Rangeland Journal 33(4):417-431. http://dx. doi.org/10.1071/RJ11031

Davies, J., R. Hill, F. J. Walsh, M. Sandford, D. Smyth, and M. C. Holmes. 2013. Innovation in management plans for Community Conserved Areas: experiences from Australian Indigenous Protected Areas. Ecology and Society 18(2): 14. http://dx.doi.org/10.5751/ES-05404-180214

Descola, P., and G. Pálsson, editors. 1996. Nature and society: anthropological perspectives. Routledge, London, UK.

Dobson, V.P., F. Walsh, J. Douglas, and Merne Altyerr-ipenhe (Food from the Creation Time) Reference Group, and J. Douglas. 2008. Anperrentye: Relationships between bush foods, creation, laws, people, country and all things, illustrated by three plants. In Desert Knowledge Symposium 2008: Developing desert directions: rethinking the future. (November 2008, Alice Springs). Desert Knowledge Cooperative Research Centre, Australia.

Drew, J. A., and A. P. Henne. 2006. Conservation biology and traditional ecological knowledge: integrating academic disciplines for better conservation practice. Ecology and Society 11(2): 34. [online] URL: http://www.ecologyandsociety. org/vol11/iss2/art34/.

Dussart, F. 2000. The politics of ritual in an aboriginal settlement: kinship, gender, and the currency of knowledge. Smithsonian Institution Press, Washington, D.C., USA.

Dussart, F. 2004. Shown but not shared, presented but not proffered: redefining ritual identity among Warlpiri ritual 
performers, 1990-2000. Australian Journal of Anthropology 15(3):253-266. http://dx.doi.org/10.1111/j.1835-9310.2004. tb00097.x

Ellen, R. F., and K. Fukui, editors. 1996. Redefining nature: ecology, culture, and domestication. Berg, Oxford, UK.

Ellen, R. F., and H. Harris. 2000. Introduction. Pages 1-29 in R. F. Ellen, P. Parkes, and A. Bicker, editors. Indigenous environmental knowledge and its transformations: critical anthropological perspectives. Harwood Academic, Amsterdam, The Netherlands.

Ens, E., and T. McDonald. 2012. Caring for country: Australian natural and cultural resource management. Ecological Management and Restoration 13(1):1. http://dx. doi.org/10.1111/j.1442-8903.2011.00633.x

Evans-Pritchard, E. E., and E. Gillies. 1976. Witchcraft, oracles, and magic among the Azande. Abridged edition. Clarendon Press, Oxford, UK.

Faulstich, P. E. 1990. Landscape perception and visual metaphor in Warlpiri world view. Dissertation. University of Hawaii at Manoa, Honolulu, Hawaii, USA.

Faulstich, P. 1994. Dreaming place: land and myth at Nyirripi. Environments: A Journal of Interdisciplinary Studies 22 (2):3-12.

Folke, C., F. S. Chapin III, and P. Olsson. 2009. Transformations in ecosystem stewardship. Pages 103-125 in F. S. Chapin III, G. P. Kofinas, and C. Folke, editors. Principles of ecosystem stewardship: resilience-based natural resource management in a changing world. Springer, New York, New York, USA. http://dx.doi.org/10.1007/978-0-387-73033-2 5

Fortmann, L. 2008. Introduction: doing science together. Pages 1-16 in L. Fortmann, editor. Participatory research in conservation and rural livelihoods: doing science together. Wiley-Blackwell, Hoboken, New Jersey, USA.

Futerra Sustainability Communications. 2010. Branding biodiversity: the new nature message. Futerra Sustainability Communications, London, UK. [online] URL: http://www. futerra.co.uk/downloads/Branding Biodiversity.pdf.

Geertz, C. 2008 [1972]. The wet and the dry: traditional irrigation in Bali and Morocco. Pages 190-201 in M. R. Dove and C. Carpenter, editors. Environmental anthropology: a historical reader. Blackwell, Oxford, UK.

Glowczewski, B. 2001. Dream trackers: Yapa art and knowledge of the Australian desert. [CD-ROM]. UNESCO, Paris, France.

Halliday, A., and M. Glaser. 2011. A management perspective on social ecological systems: a generic system model and its application to a case study from Peru. Research in Human
Ecology 18(1):1-18. [online] URL: http://www.humanecologyreview. org/pastissues/her181/halliday.pdf.

Head, L., D. Trigger, and E. Woodward. 2004. Nature, culture and the challenges of environmental sustainability: bridging the science/humanities divide. An Australian Research Council special research initiative. University of Wollongong, Wollongong, Australia.

Hill, R., F. Walsh, J. Davies, and M. Sandford. 2011. Our country our way: guidelines for Australian Indigenous Protected Area management plans. CSIRO, Cairns, Australia. [online] URL: http://www.environment.gov.au/indigenous/ ipa/toolkit/management.html.

Hogan, M. 2006. Kanyini. [DVD]. Northern Territory Film Office, Alice Springs, Australia.

Holmes, M. C. C. 2010. Law for country: the structure and application of Warlpiri ecological knowledge. Dissertation. University of Queensland, St. Lucia, Australia.

Hoogenraad, R., and G. J. Robertson. 1997. Seasonal calendars from central Australia. Pages 34-41 in E. K. Webb, editor. Windows on meteorology: Australian perspective. CSIRO Publishing, Collingwood, Australia.

Horton, D., editor. 1994. The encyclopaedia of Aboriginal Australia: Aboriginal and Torres Strait Islander history, society and culture. Aboriginal Studies Press for the Australian Institute of Aboriginal and Torres Strait Islander Studies, Canberra, Australia.

Houde, N. 2007. The six faces of traditional ecological knowledge: challenges and opportunities for Canadian comanagement arrangements. Ecology and Society 12(2): 34. [online] URL: http://www.ecologyandsociety.org/vol12/iss2/ art34.

Huntington, H. P., S. F. Trainor, D. C. Natcher, O. H. Huntington, L. DeWilde, and F. S. Chapin III. 2006. The significance of context in community-based research: understanding discussions about wildfire in Huslia, Alaska. Ecology and Society 11(1): 40. [online] URL: http://www. ecologyandsociety.org/vol11/iss1/art40.

Ingold, T. 2000. The perception of the environment: essays on livelihood, dwelling and skill. Routledge, London, UK.

Jackson, M. 1995. At home in the world. Duke University Press, Durham, North Carolina, USA.

Johnson, L. M., and E. S. Hunn, editors. 2010a. Landscape ethnoecology: concepts of biotic and physical space. Berghahn Books, New York, New York, USA.

Johnson, L. M., and E. S. Hunn. 2010b. Landscape ethnoecology: reflections. Pages 279-297 in L. M. Johnson and E. S. Hunn, editors. Landscape ethnoecology: concepts 
of biotic and physical space. Berghahn Books, New York, New York, USA.

Latz, P. 1995. Bushfires and bushtucker: Aboriginal people and plant use in central Australia. IAD Press, Alice Springs, Australia.

Laughren, M., K. L. Hale, and Warlpiri Lexicology Group. 2005. Warlpiri-English encyclopaedic dictionary. University of Queensland, Brisbane, Australia.

Low Choy, D., J. Wadsworth, and D. Burns. 2010. Seeing the landscape through new eyes: identifying and incorporating indigenous landscape values into regional planning processes. Australian Planner 47(3):178-190. [online] URL: http:// www.tandfonline.com/doi/abs/10.1080/07293682.2010.509337. http://dx.doi.org/10.1080/07293682.2010.509337

Maddock, K. 1972. The Australian Aborigines: a portrait of their society. Allen Lane, London, UK.

Meggitt, M. J. 1962. Desert people: a study of the Walbiri Aborigines of central Australia. Angus and Robertson, Sydney, Australia.

Meggitt, M. 1972. Understanding Australian Aboriginal society: kinship systems or cultural categories? Pages 64-87 in P. Reining, editor. Kinship studies in the Morgan centennial year. Anthropological Society of Washington, Washington, D.C., USA.

Moyle, R. M. 1997. Balgo: the musical life of a desert community. Callaway International Resource Centre for Music Education, Nedlands, Australia.

Munn, N. D. 1984. The transformation of subjects into objects in Walbiri and Pitjantjatjara myth. Pages 56-82 in $\mathrm{M}$. Charlesworth, H. Morphy, D. Bell, and K. Maddock, editors. Religion in Aboriginal Australia: an anthology. University of Queensland Press, St. Lucia, Australia.

Munn, N. D. 1996. Excluded spaces: the figure in the Australian Aboriginal landscape. Critical Inquiry 22 (3):446-465. http://dx.doi.org/10.1086/448801

Murphee, M. W. 2008. Forward. Pages xvi-xxii in L. Fortmann, editor. Participatory research in conservation and rural livelihoods: doing science together. Wiley-Blackwell, Hoboken, New Jersey, USA.

Myers, F. R. 1986. Pintupi country, Pintupi self: sentiment, place, and politics among Western Desert Aborigines. Smithsonian Institution Press, Washington, D.C., USA.

North Australian Indigenous Land and Sea Management Alliance. 2006. Indigenous ecological knowledge: a Northern Territory scoping study. Report for the Northern Territory Natural Resource Management Board. North Australian Indigenous Land and Sea Management Alliance, Darwin, Australia.
O'Connell, J. F., P. K. Latz, and P. Barnett. 1983. Traditional and modern plant use among the Alyawara of central Australia. Economic Botany 37(1):80-109. http://dx.doi.org/10.1007/ BF02859310

O'Neill, C., D. Green, and W. Lui. 2012. How to make climate change research relevant for Indigenous communities in Torres Strait, Australia. Local Environment 17(10):1104-1120. http://dx.doi.org/10.1080/13549839.2012.716405

Pawu-Kurlpurlurnu, W. J., M. Holmes, and L. A. Box. 2008. Ngurra-kurlu: a way of working with Warlpiri people. Desert Knowledge CRC report 41. Desert Knowledge CRC, Alice Springs, Australia. [online] URL: http://www.desertknowledgecrc. com.au/resource/DKCRC-Report-41-Ngurra-kurlu.pdf.

Prober, S. M., M. H. O'Connor, and F. J. Walsh. 2011. Australian Aboriginal peoples' seasonal knowledge: a potential basis for shared understanding in environmental management. Ecology and Society 16(2): 12. [online] URL: http://www.ecologyandsociety.org/vol16/iss2/art12/.

Putnis, A., P. Josif, and E. Woodward. 2007. Healthy country, healthy people: supporting indigenous engagement in the sustainable management of Northern Territory land and seas: a strategic framework. CSIRO, Darwin, Australia. [online] URL: http://www.csiro.au/en/Outcomes/Environment/Biodiversity/ HealthyCountryHealthyPeopleReport.aspx.

Radcliffe-Brown, A. R. 1926. The Rainbow-Serpent myth of Australia. Journal of the Royal Anthropological Institute of Great Britain and Ireland 56:19-25. [online] URL: http:// www.scribd.com/doc/38527584/Rainbow-Serpent. http://dx. doi.org/10.2307/2843596

Rappaport, R. A. 1968. Pigs for the ancestors: ritual in the ecology of a New Guinea people. Yale University Press, New Haven, Connecticut, USA.

Rose, B. 1995. Land management issues: attitudes and perceptions amongst Aboriginal people of central Australia. Central Land Council, Alice Springs, Australia.

Sathre, E. L. 2003. Everyday illness: discourse, action, and experience in the Australian desert. Dissertation. Australian National University, Canberra, Australia.

Sluka, J. A., and A. C. G. M. Robben. 2007. Fieldwork in cultural anthropology: an introduction. Pages 1-28 in A. C. G. M. Robben and J. A. Sluka, editors. Ethnographic fieldwork: an anthropological reader. Blackwell, Malden, Massachusetts, USA.

Stanner, W. E. H. 1969. After the dreaming: black and white Australians: an anthropologist's view. Australian Broadcasting Commission, Sydney, Australia. 
Stewart, S. 1995. Participatory rural appraisal: abstracts of sources: an annotated bibliography. Institute of Development Studies, Brighton, UK.

Strang, V. 2005. Knowing me, knowing you: Aboriginal and European concepts of nature as self and other. Worldviews: Global Religions, Culture, and Ecology 9(1):25-56. http://dx. doi.org/10.1163/1568535053628463

Swanson, F. J., and F. S. Chapin III. 2009. Forest systems: living with long-term change. Pages 149-170 in F. S. Chapin III, G. P. Kofinas, and C. Folke, editors. Principles of ecosystem stewardship: resilience-based natural resource management in a changing world. Springer, New York, New York, USA. http://dx.doi.org/10.1007/978-0-387-73033-2 7

Usher, P. J. 2000. Traditional ecological knowledge in environmental assessment and management. Arctic 53 (2):183-193.

Walker, B. H., L. H. Gunderson, A. P. Kinzig, C. Folke, S. R. Carpenter, and L. Schultz. 2006. A handful of heuristics and some propositions for understanding resilience in socialecological systems. Ecology and Society 11(1): 13. [online] URL: http://www.ecologyandsociety.org/vol11/iss1/art13/.

Walker, B. H., and D. Salt. 2006. Resilience thinking: sustaining ecosystems and people in a changing world. Island Press, Washington, D.C., USA.

Walsh, F. 2000. Land use and management issues identified by Aboriginal people in central Australia and potential socioeconomic indicators of sustainable land use. Land Assessment and Planning Unit, Central Land Council, Alice Springs, Australia.

Walsh, F. J., P. V. Dobson, and J. C. Douglas. 2013. Anpernirrentye: a framework for enhanced application of indigenous ecological knowledge in natural resource management. Ecology and Society 18(3): 18. http://dx.doi. org/10.5751/ES-05501-180318

Williams, N. M., and G. Baines, editors. 1993. Traditional ecological knowledge: wisdom for sustainable development. Centre for Resource and Environmental Studies, Australian National University, Canberra, Australia.

Woodward, E. 2008. Social networking for Aboriginal land management in remote northern Australia. Australasian Journal of Environmental Management 15(4):241-252. http:// dx.doi.org/10.1080/14486563.2008.10648753 